\title{
Tonotopic Variation in the Calcium Dependence of Neurotransmitter Release and Vesicle Pool Replenishment at Mammalian Auditory Ribbon Synapses
}

\author{
Stuart L. Johnson, ${ }^{1}$ Andrew Forge, ${ }^{2}$ Marlies Knipper, ${ }^{3}$ Stefan Münkner, ${ }^{4}$ and Walter Marcotti ${ }^{1}$ \\ ${ }^{1}$ Department of Biomedical Science, University of Sheffield, Sheffield S10 2TN, United Kingdom, ${ }^{2}$ Centre for Auditory Research, UCL Ear Institute, \\ University College London, London WC1X 8EE, United Kingdom, ${ }^{3}$ Department of Otolaryngology, Molecular Neurobiology, Tübingen Hearing Research \\ Center, and ${ }^{4}$ Institute of Physiology II, University of Tübingen, D-72076 Tübingen, Germany
}

\begin{abstract}
The mammalian cochlea is specialized to recognize and process complex auditory signals with remarkable acuity and temporal precision over a wide frequency range. The quality of the information relayed to the auditory afferent fibers mainly depends on the transfer characteristics of inner hair cell (IHC) ribbon synapses. To investigate the biophysical properties of the synaptic machinery, we measured changes in membrane capacitance $\left(\Delta C_{\mathrm{m}}\right)$ in low-frequency (apical region, $\sim 300 \mathrm{~Hz}$ ) and high-frequency (basal, $\left.\sim 30 \mathrm{kHz}\right)$ gerbil IHCs maintained in near physiological conditions ( $1.3 \mathrm{~mm}$ extracellular $\mathrm{Ca}^{2+}$ and body temperature). With maturation, the $\mathrm{Ca}^{2+}$ efficiency of exocytosis improved in both apical and basal IHCs and was more pronounced in the latter. Prehearing IHCs showed a similar Ca ${ }^{2+}$ cooperativity of exocytosis despite the smaller $\Delta C_{\mathrm{m}}$ in apical cells. After maturation, $\Delta C_{\mathrm{m}}$ in high-frequency IHCs increased linearly with the $\mathrm{Ca}^{2+}$ current, whereas, somewhat surprisingly, the relationship was significantly more nonlinear in low-frequency cells. This tonotopic difference seemed to be correlated with ribbon synapse morphology (spherical in apical and ellipsoid in basal IHCs) but not with the expression level of the proposed $\mathrm{Ca}^{2+}$ sensor otoferlin or the spatial coupling between $\mathrm{Ca}^{2+}$ channels and active zones. Repetitive stimulation of adult IHCs showed that vesicle pool refilling could become rate limiting for vesicle release, with high-frequency IHCs able to sustain greater release rates. Together, our findings provide the first evidence for a tonotopic difference in the properties of the synaptic machinery in mammalian IHCs, which could be essential for fine-tuning their receptor characteristics during sound stimulation.
\end{abstract}

Key words: hair cell; ribbon synapse; exocytosis; development; cochlea; calcium current

\section{Introduction}

The exquisite temporal acuity of the mammalian cochlea depends on neurotransmitter release at inner hair cell (IHC) ribbon synapses onto auditory afferent fibers (Fuchs, 2005). Ribbon synapses are specialized structures capable of tethering numerous synaptic vesicles at the release sites of IHCs and photoreceptors (Sterling and Matthews, 2005), allowing them to facilitate high rates of sustained synaptic transmission and coordinated release of vesicles [mammals (Glowatzki and Fuchs, 2002; Goutman and Glowatzki, 2007; Neef et al., 2007); bullfrog (Keen and Hudspeth, 2006)]. Therefore, the ability to relay information with highfidelity to the central auditory pathway is primarily determined by the transfer characteristics at IHC ribbon synapses. This is dependent on vesicle fusion triggered by $\mathrm{Ca}^{2+}$ entry through

Received Feb. 21, 2008; revised May 28, 2008; accepted June 17, 2008.

This work was supported by the Wellcome Trust, Deafness Research UK, and The Royal Society. W.M. is a Royal Society University Research Fellow. We would like to thank A. J. Ricci for his critical feedback on this manuscript. We would also like to thank $\mathrm{G}$. Nevill for his excellent technical assistance in preparing sections for TEM, as well as $\mathrm{M}$. Cardwell and B. J. Chappell for their excellent assistance with the animals.

This article is freely available online through the J Neurosci Open Choice option.

Correspondence should be addressed to Dr. Walter Marcotti, Department of Biomedical Science, University of Sheffield, Sheffield S10 2TN, UK. E-mail: w.marcotti@sheffield.ac.uk.

DOI:10.1523/JNEUROSCI.0785-08.2008

Copyright $\odot 2008$ Society for Neuroscience $\quad$ 0270-6474/08/287670-09\$15.00/0
L-type $\left(\mathrm{Ca}_{\mathrm{V}} 1.3\right) \mathrm{Ca}^{2+}$ channels (Platzer et al., 2000) clustered at the presynaptic active zones (Roberts et al., 1990; Tucker and Fettiplace, 1995). Although mature IHCs respond to sound stimuli with graded receptor potentials (Cody and Russell, 1987), prehearing cells (approximately P12 in most rodents) fire spontaneous $\mathrm{Ca}^{2+}$-dependent action potentials (APs) (Beutner and Moser, 2001; Marcotti et al., 2003a,b). In order for IHC synaptic transmission to be optimally configured for the different receptor characteristics during immature and adult stages of development, their synaptic machinery has to change extensively (Sobkowicz et al., 1982; Moser et al., 2006). Biophysically, ribbon synapses become more $\mathrm{Ca}^{2+}$ efficient (Beutner and Moser, 2001; Johnson et al., 2005) and less $\mathrm{Ca}^{2+}$ dependent (Johnson et al., 2005 ) with maturation, possibly allowing adult IHCs to respond best to continuous and graded stimuli and at the same time broaden their dynamic range.

The sensory neuroepithelium of vertebrate auditory organs is tonotopically organized such that the characteristic frequency (CF) of hair cells (the sound frequency at which they respond best) gradually changes with position along the auditory organ. In lower vertebrates, this is intrinsically dictated by a positiondependent variation in the biophysical properties of the hair cells (Fettiplace and Fuchs, 1999). Because the mechanical tuning of the mammalian cochlea is thought to provide the necessary fre- 
quency selectivity and sensitivity, IHCs are as yet not considered to be intrinsically tuned themselves or to show great tonotopic variation in their properties. However, recent studies have shown such variation in some intrinsic IHC biophysical properties $\left[\mathrm{Ca}^{2+}\right.$-buffering proteins (Hackney et al., 2005); transducer current (Jia et al., 2007); $\mathrm{Ca}^{2+}$ current (Johnson and Marcotti, 2008)]. Despite the central role for IHC synaptic machinery in auditory transduction, there remains a dearth of information regarding the tonotopicity of its biophysical properties. Therefore, we investigated the kinetics and $\mathrm{Ca}^{2+}$ dependence of vesicle release in low- and high-frequency gerbil IHCs in situ using near physiological recording conditions. Our main findings indicate the existence of tonotopic differences in the $\mathrm{Ca}^{2+}$ dependence of exocytosis and vesicle pool replenishment at IHC ribbon synapses with high-frequency cells being more indefatigable than low-frequency cells. The information presented here provides the first evidence for a position-dependent synaptic specialization, the function of which could be to optimize the responses of these auditory receptors.

\section{Materials and Methods}

Electrophysiology. Low- and high-frequency IHCs $(n=120)$ from gerbils were studied in acutely dissected organs of Corti from postnatal day 20 (P20) to P69, at which the day of birth is P0. The average age in apical and basal IHCs was P38 and P42, respectively, which is considered to be mature (Woolf and Ryan, 1984; Müller, 1996). A few prehearing apical and basal IHCs were also investigated ( $n=18$; P5-P7). Gerbils were killed by cervical dislocation in accordance with UK Home Office regulations. Cochleae were dissected in normal extracellular solution (in mм): $135 \mathrm{NaCl}, 5.8 \mathrm{KCl}, 1.3 \mathrm{CaCl}_{2}, 0.9 \mathrm{MgCl}_{2}, 0.7 \mathrm{NaH}_{2} \mathrm{PO}_{4}, 5.6$ D-glucose, $10 \mathrm{HEPES}-\mathrm{NaOH}$. Sodium pyruvate $(2 \mathrm{~mm})$, amino acids, and vitamins were added from concentrates (Thermo Fisher Scientific). The $\mathrm{pH}$ was adjusted to 7.5 (osmolality $\sim 308 \mathrm{mmol} \mathrm{kg}{ }^{-1}$ ). The dissected cochleae were viewed using an upright microscope (Leica Microsystems) with Nomarski differential interference contrast optics. Adult IHCs were positioned at a frequency range of $250-420 \mathrm{~Hz}$ in apical and $20-37 \mathrm{kHz}$ in basal cells (Müller, 1996).

Whole-cell patch-clamp recordings were performed at body temperature $\left(34-37^{\circ} \mathrm{C}\right)$ using an Optopatch amplifier (Cairn Research). Patch pipettes (2-3 M $\Omega$ ) were coated with surfwax (Mr. Zogs Sex Wax) and contained the following (in mM): 106 Cs-glutamate, $20 \mathrm{CsCl}, 3 \mathrm{MgCl}_{2}, 1$ EGTA-CsOH, $5 \mathrm{Na}_{2}$ ATP, $0.3 \mathrm{Na}_{2} \mathrm{GTP}, 5$ HEPES-CsOH, $10 \mathrm{Na}_{2}-$ phosphocreatine ( $\mathrm{pH} 7.3 ; 294 \mathrm{mmol} \mathrm{kg}^{-1}$ ). In some cases, 1 mM EGTA was replaced by different BAPTA concentrations $(0.1,0.3,0.6,1$, and 5 $\mathrm{mM}$ ), and when necessary, $\mathrm{CsCl}$ was adjusted to keep the osmolality constant. In a few experiments, perforated patch was used, and the pipette-filling solution contained the following (in $\mathrm{mM}$ ): $110 \mathrm{~K}$-aspartate, $21 \mathrm{CsCl}, 3 \mathrm{MgCl}_{2}, 5 \mathrm{Na}_{2} \mathrm{ATP}, 1$ EGTA or 1 BAPTA, 5 HEPES-CsOH, 10 $\mathrm{Na}_{2}$-phosphocreatine ( $\mathrm{pH} 7.3 ; 295 \mathrm{mmol} \mathrm{kg}^{-1}$ ). The antibiotic amphotericin B (Merck) was dissolved in dry DMSO before dilution in the above intracellular solution to 120 or $240 \mu \mathrm{g} \mathrm{ml}^{-1}$ (Johnson et al., 2007).

Real-time changes in membrane capacitance $\left(\Delta C_{\mathrm{m}}\right)$ were measured as described previously (Johnson et al., 2002, 2005). Briefly, a $4 \mathrm{kHz}$ sine wave of $13 \mathrm{mV}$ rms was applied to IHCs from $-81 \mathrm{mV}$ and was interrupted for the duration of the voltage $(V)$ step. The capacitance signal from the Optopatch was filtered at $250 \mathrm{~Hz}$ and sampled at $5 \mathrm{kHz} . \Delta C_{\mathrm{m}}$ was measured by averaging the $C_{\mathrm{m}}$ trace over a $200 \mathrm{~ms}$ period after the voltage step and subtracting the prepulse baseline. Data were acquired using pClamp software and a Digidata 1320A (Molecular Devices) and analyzed with Origin (OriginLab). Calcium currents were corrected offline for the linear leak conductance $(1.7 \pm 0.1 \mathrm{nS} ; n=135$; P5-P69). Membrane potentials were corrected for the voltage drop across the series resistance $(5.2 \pm 0.1 \mathrm{M} \Omega ; n=136)$ and a liquid junction potential of $-11 \mathrm{mV}$, measured between electrode and bath solutions. The average voltage-clamp time constant (product of $R_{\mathrm{s}}$ and cell membrane capacitance $\left.C_{\mathrm{m}}, 10.2 \pm 0.1 \mathrm{pF} ; n=137\right)$ was $54 \pm 1 \mu \mathrm{s}(n=136)$.

Experiments were performed in the presence of $30 \mathrm{~mm}$ tetraethylam- monium and 15 mm 4-AP (Fluka) to block $I_{\mathrm{K}, \mathrm{f}}$ (Kros et al., 1998) and delayed rectifier $\mathrm{K}^{+}$currents $\left[I_{\mathrm{K}, \text { neo }}\right.$ and $I_{\mathrm{K}, \mathrm{s}}$ (Marcotti et al., 2003a)]. Apamin (used for some experiments at $300 \mathrm{nM}$; Merck) and linopirdine (80-100 $\mu \mathrm{M}$; Tocris Bioscience) were also used to block $I_{\mathrm{SK}}$ in immature (Marcotti et al., 2004) and $I_{\mathrm{K}, \mathrm{n}}$ in adult (Marcotti et al., 2003a) IHCs, respectively. The $\mathrm{Ca}^{2+}$ dependence of $\Delta C_{\mathrm{m}}$ was studied by superfusing a $\mathrm{Ca}^{2+}$-free solution (containing $0.5 \mathrm{~mm}$ EGTA) or different $\mathrm{Ca}^{2+}$ concentrations $(0.6,1.3,2.5,5$, and $10 \mathrm{~mm})$. When the concentration of blockers or $\mathrm{Ca}^{2+}$ that were added to or removed from the solution was $>1 \mathrm{~mm}, \mathrm{NaCl}$ was adjusted to keep the osmolality constant.

Statistical comparisons of means were made by the two-tailed $t$ test or, for multiple comparisons, one-way ANOVA followed by Tukey's test. Two-way ANOVA, followed by the Bonferroni test, was used to compare data sets from apical and basal IHCs. Means are quoted \pm SEM, and $p<$ 0.05 indicates statistical significance.

Immunocytochemistry. For immunofluorescence microscopy, the cochleae from adult gerbils were dissected and processed as described previously (Schug et al., 2006). Otoferlin (mouse monoclonal; Biozol), CtBP2 (rabbit polyclonal; Proteintech Group), and polyclonal antiNeurofilament 200 (NF200; Sigma-Aldrich) antibodies were used for immunostaining. Primary antibodies were detected with cyanine-3conjugated (Jackson ImmunoResearch Laboratories) or Alexa Fluor 488-conjugated antibodies (Invitrogen). Sections were embedded with Vectashield mounting medium with 4', $6^{\prime}$-diamidino-2-phenylindole dihydrochloride (DAPI) (Vector Laboratories) and viewed using an Olympus AX70 microscope equipped with epifluorescence illumination. Images were acquired using a CCD camera and the imaging system analySIS (Soft Imaging System) and processed with Adobe Photoshop. CtBP2immunopositive ribbons were counted from apical and midbasal IHCs from six gerbils of three different age groups between P22 and 12 months. The distribution of otoferlin in apical and basal IHCs was determined in at least three animals of a given age (P22, P43, and P120) and done at least in triplicate on each.

Electron microscopy. Apical and basal IHCs from P34 gerbil cochleae were fixed by direct perfusion in $2.5 \%$ glutaraldehyde in $0.1 \mathrm{M}$ cacodylate buffer, $\mathrm{pH} 7.3$, for $2 \mathrm{~h}$, washed three times in the above buffer, and then decalcified in $4.13 \%$ EDTA, pH 7.3, for $2 \mathrm{~d}$ at $4^{\circ} \mathrm{C}$. Cochleae were then postfixed $(2 \mathrm{~h})$ in buffered $1 \% \mathrm{OsO}_{4}$, partially dehydrated by an ethanol series up to $70 \%$, at which point the cochleae were incubated in saturated uranyl acetate (70\% ethanol) overnight, before completing the ethanol dehydration. The whole intact, decalcified cochlea was embedded in plastic and sectioned in a plane parallel to modiolus. At a near mid modiolar location, thin sections that included the entire height of the cochlea were taken and mounted on Formvar-coated single slot grids, so that sections through both the apical and the basal coil were included in a single thin section. Serial thin sections of $100 \mathrm{~nm}$ thickness of the entire cochlea were then cut as closely as possible parallel to the modiolus and each section mounted on a different grid. All sections were stained with uranyl acetate and lead citrate. The sections at the level close to the modiolus itself were investigated so that the longitudinal sections of basal and apical IHCs examined were in approximately the same orientation to the plane of sectioning. The serial sections were displayed in sequence so that most ribbons could be visualized in their entirety. Basal and apical IHCs from the same sections were examined. Synaptic ribbons were visualized from three apical $(n=10)$ and two basal IHCs $(n=16)$. Ribbon dimensions were taken from those captured in a micrograph and oriented to give an accurate measurement (apical, $n=6$; basal, $n=9$ ).

\section{Results}

Whole-cell patch-clamp recordings were used to investigate $\mathrm{Ca}^{2+}$-dependent exocytosis in low-frequency $(\sim 300 \mathrm{~Hz})$ and high-frequency $(\sim 30 \mathrm{kHz})$ gerbil inner hair cells maintained in situ in near physiological conditions (body temperature and 1.3 $\mathrm{mm}$ extracellular $\mathrm{Ca}^{2+}$ ). Synaptic vesicle exocytosis was measured as an increase in cell $C_{\mathrm{m}}$ that is interpreted as a sign of neurotransmitter release from presynaptic cells (Parsons et al., 1994; von Gersdorff et al., 1996; Moser and Beutner, 2000). 
A

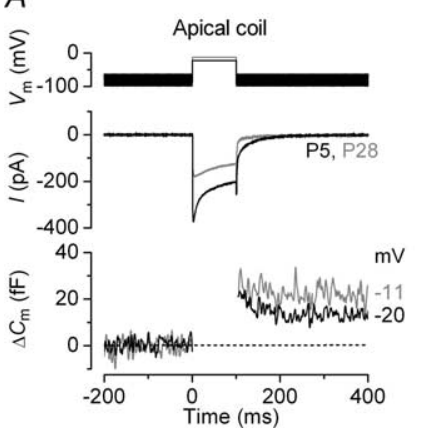

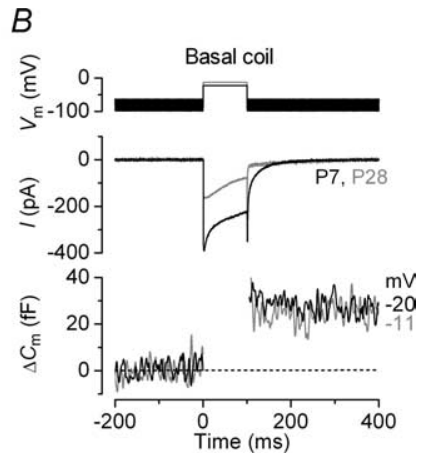

Figure 1. Increased $\mathrm{Ca}^{2+}$ efficiency of exocytosis in gerbil IHCs during maturation. $A, B, I_{\mathrm{Ca}}$ (middle) and $\Delta C_{m}$ (bottom) responses recorded from immature (black traces) and adult (gray traces) IHCs positioned in apical and basal regions of the cochlea, respectively. Recordings were obtained in response to $100 \mathrm{~ms}$ voltage steps from the holding potential of $-81 \mathrm{to}-20 \mathrm{mV}$ or $-11 \mathrm{mV}$, where the peak of the $I-V$ curve occurred (Figs. $2 B, 3 B$, bottom). The voltage protocol is shown above the traces. Unless otherwise stated, all recordings were at body temperature and used physiological $1.3 \mathrm{~mm}$ extracellular $\mathrm{Ca}^{2+}$.

\section{Position-dependent variation in the $\mathrm{Ca}^{2+}$ dependence of exocytosis}

Recent studies on mouse apical IHCs (frequency range, $\sim 3-5$ $\mathrm{kHz}$ ) have shown that the coupling between $\mathrm{Ca}^{2+}$ channels and the synaptic machinery becomes more efficient from around the onset of hearing (Beutner and Moser, 2001; Johnson et al., 2005). Therefore, we first investigated whether gerbil IHCs follow a similar developmental pattern. Figure $1 A, B$ shows the maximal $\mathrm{Ca}^{2+}$ current $\left(I_{\mathrm{Ca}}\right)$ and the corresponding $\Delta C_{\mathrm{m}}$ recorded in apical and basal IHCs, respectively, at immature and adult stages of development. Although the size of $I_{\mathrm{Ca}}$ decreased in both cochlear regions with maturation, the induced $\Delta C_{\mathrm{m}}$ was comparable throughout development indicative of an increase in the $\mathrm{Ca}^{2+}$ efficiency of exocytosis (qualitatively judged to be $\Delta C_{\mathrm{m}} / I_{\mathrm{Ca}}$ ). This is suggestive of a common physiological maturation of the IHC synaptic machinery between species. Currently, there is a complete absence of information regarding any position-dependent difference in the properties of neurotransmitter release in IHCs, which if found could greatly improve our understanding of how auditory signals are encoded at the first synapse in the auditory pathway. For these experiments, the gerbil was preferred to the more commonly used mouse because of its extended lowfrequency hearing range, which would emphasize any tonotopic differences (gerbil, $\sim 0.1-60 \mathrm{kHz}$; mouse, $\sim 2-100 \mathrm{kHz}$ ) (Greenwood, 1990; Müller, 1996).

A direct comparison of $I_{\mathrm{Ca}}$ and the corresponding $\Delta C_{\mathrm{m}}$ from apical and basal immature IHCs is shown in Figure $2 A$. Although the size of $I_{\mathrm{Ca}}$ was similar between IHCs (apical, $-334 \pm 23 \mathrm{pA}$, $n=9$, P5-P6; basal, $-272 \pm 25 \mathrm{pA}, n=7$, P6-P7) (Fig. $2 B$, bottom) (see also Johnson and Marcotti, 2008), the induced $\Delta C_{\mathrm{m}}$ was found to be significantly larger in basal $(30 \pm 3 \mathrm{fF})$ than in apical cells $(14 \pm 1 \mathrm{fF} ; p<0.0001)$ (Fig. $2 \mathrm{~B}$, top), indicative of a lower $\mathrm{Ca}^{2+}$ efficiency of exocytosis in the latter. The synaptic transfer functions (Augustine et al., 1985; Johnson et al., 2005), illustrating the $\mathrm{Ca}^{2+}$ dependence of exocytosis (defined as the change in $\Delta C_{\mathrm{m}}$ as a function of $I_{\mathrm{Ca}}$ ) (Eq. 1), are shown in Figure $2 C$. For this comparison, peak $I_{\mathrm{Ca}}$ was preferred to its time integral because, for voltage steps longer than a few tens of milliseconds and at positive membrane potentials, $I_{\mathrm{Ca}}$ could be contaminated by the presence of residual unblocked $\mathrm{K}^{+}$currents (Johnson et al., 2005, 2007). $I_{\mathrm{Ca}}$ inactivation would not affect our interpretations because it has recently been shown to be similar in apical and basal immature IHCs (Johnson and Marcotti, 2008). Data shown in Figure $2 C$ were approximated using a power function:

$$
\Delta C_{\mathrm{m}}=c I_{\mathrm{Ca}}{ }^{N},
$$

where $c$ is a scaling coefficient, and the exponent $N$ is the power. The power obtained from fitting the data from prehearing IHCs (apical, $3.8 \pm 0.3, n=9$; basal, $3.8 \pm 0.4, n=7$ ) indicates that at least four $\mathrm{Ca}^{2+}$ ions have to cooperatively bind to the $\mathrm{Ca}^{2+}$ sensor to trigger a release event (Dodge and Rahamimoff, 1967; Johnson et al., 2005). This suggests that apical and basal IHCs exhibit a comparable $\mathrm{Ca}^{2+}$ dependence of exocytosis despite the smaller $\Delta C_{\mathrm{m}}$ in the former. The lower $\mathrm{Ca}^{2+}$ efficiency of exocytosis in apical IHCs could be a consequence of fewer vesicles and/or ribbons or more extrasynaptic $\mathrm{Ca}^{2+}$ channels compared with basal cells.

Calcium currents and corresponding $\Delta C_{\mathrm{m}}$ recordings from low- and high-frequency adult IHCs are shown in Figure $3 A$. Both the size of the peak $I_{\mathrm{Ca}}$ at $-11 \mathrm{mV}$ (apical, $-151 \pm 8 \mathrm{pA}, n=$ 15; basal, $-145 \pm 10 \mathrm{pA}, n=13$ ) (Fig. $3 B$, bottom) and the induced $\Delta C_{\mathrm{m}}$ (apical, $20 \pm 2 \mathrm{fF}$; basal, $22 \pm 1 \mathrm{fF}$ ) (Fig. $3 B$, top) were similar between apical and basal IHCs. The power value of the synaptic transfer function in basal IHCs $(\sim 30 \mathrm{kHz})$ was $1.0 \pm$ $0.1(n=13)$ (Fig. 3C,D, bottom), suggesting a linear relationship between $\mathrm{Ca}^{2+}$ entry and exocytosis similar to previous findings in apical adult mouse IHCs $(\sim 3-5 \mathrm{kHz})$ (Brandt et al., 2005; Johnson et al., 2005, 2007) and hair cells of the turtle auditory papilla $(\sim 100-300 \mathrm{~Hz})$ (Schnee et al., 2005). Surprisingly, the power value of adult apical $(300 \mathrm{~Hz})$ gerbil IHCs was significantly higher $(2.2 \pm 0.2 ; n=15 ; p<0.0001)$ (Fig. $3 C, D$, top) than that of basal cells, to some extent resembling that measured in prehearing gerbil cells. It is possible that a proportion of $I_{\mathrm{Ca}}$ in IHCs (>90\% carried by $\mathrm{Ca}_{\mathrm{v}} 1.3$ ) (Platzer et al., 2000; Brandt et al., 2003) is driven by $\mathrm{Ca}^{2+}$ channels not directly linked to the exocytotic machinery, the distribution of which could differ along the cochlea. However, this is unlikely to affect our results because the theoretical removal of this homogeneous population of channels would possibly compress the transfer functions but not change their power values. A change in the $\mathrm{Ca}^{2+}$ dependence of exocytosis would only occur if one or more additional types of $\mathrm{Ca}^{2+}$ channel with different voltage-dependent properties and not coupled to vesicle release were expressed in IHCs. Because apical and basal adult gerbil IHCs show a small but significantly different degree of $I_{\mathrm{Ca}}$ inactivation (Johnson and Marcotti, 2008), the capacitance synaptic transfer functions (Fig. 3C) were re-plotted using the time integral of $I_{\mathrm{Ca}}$ to represent the total $\mathrm{Ca}^{2+}$ entry during the $100 \mathrm{~ms}$ steps. The power values obtained using $I_{\mathrm{Ca}}$ integrals (apical IHCs, $2.5 \pm 0.2$; basal IHCs, $1.2 \pm 0.1$; data not shown) were comparable with those obtained using peak $I_{\mathrm{Ca}}$, suggesting that the amount of $\mathrm{Ca}^{2+}$ seen by the synaptic machinery was not significantly affected by $I_{\mathrm{Ca}}$ inactivation.

Recent investigations have suggested that the opening of each $\mathrm{Ca}^{2+}$ channel allows sufficient $\mathrm{Ca}^{2+}$ entry to initiate the release of only very nearby vesicles (Neher, 1998; Brandt et al., 2005). Therefore, the amount of vesicles released summates with the voltage-dependent activation of $\mathrm{Ca}^{2+}$ channels. This would give the impression of a linear $\mathrm{Ca}^{2+}$ dependence of exocytosis although the machinery may have intrinsically higher-order dependence, which becomes evident at positive membrane potentials (Brandt et al., 2005). Assuming that the intracellular $\mathrm{Ca}^{2+}$ concentration at the release site is proportional to the singlechannel current (Naraghi and Neher, 1997), the intrinsic $\mathrm{Ca}^{2+}$ 
A

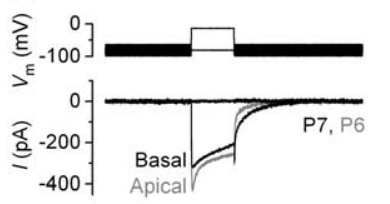

$B$

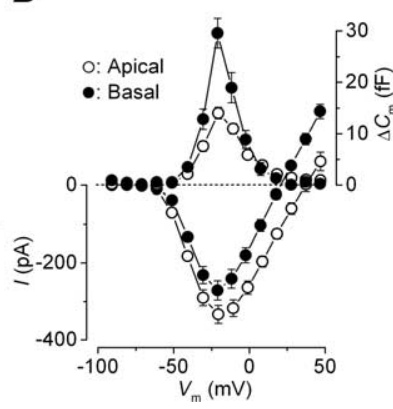

C

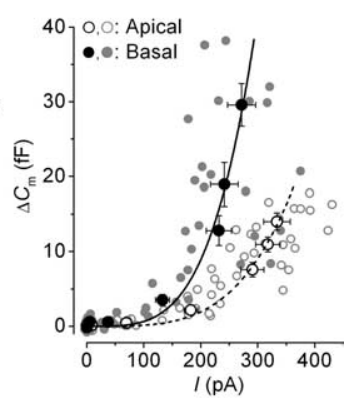

Figure 2. $\mathrm{Ca}^{2+}$ currents and $\Delta C_{\mathrm{m}}$ in prehearing gerbil $\mathrm{HHC}$. $A, I_{\mathrm{Ca}}$ and $\Delta C_{\mathrm{m}}$ responses recorded from immature apical (gray traces) and basal (black traces) IHCs. Recordings were obtained in response to $100 \mathrm{~ms}$ voltage steps from -81 in $10 \mathrm{mV}$ nominal increments. For clarity, only responses at -81 and $-20 \mathrm{mV}$ are shown. $B$, Average peak $I-V$ (bottom) and $\Delta C_{\mathrm{m}}-V$ (top) curves from apical (P5-P6; $n=9$ ) and basal (P6-P7; $n=7$ ) IHCs. C, Synaptic transfer functions obtained by plotting average $\Delta C_{\mathrm{m}}$ against the corresponding $I_{\mathrm{Ca}}$ between $-71 \mathrm{mV}$ and near $-11 \mathrm{mV}$ from $\boldsymbol{B}$ for apical and basal IHCs. Single data points (gray circles) are also shown. The fits are according to Equation 1. Error bars indicate SEM.

A
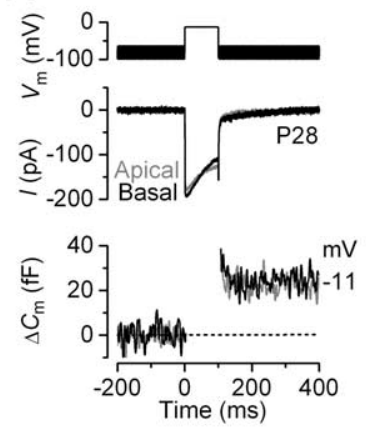

C

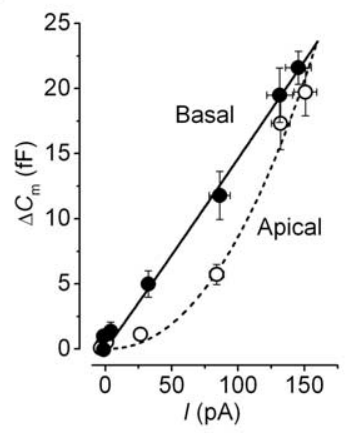

E

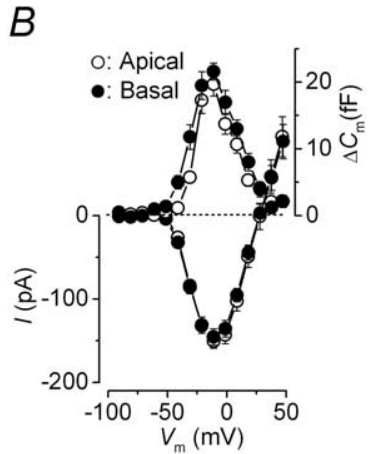

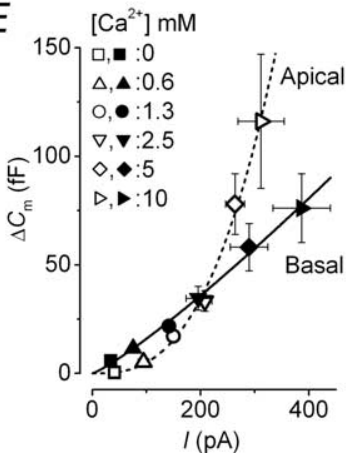

$D$
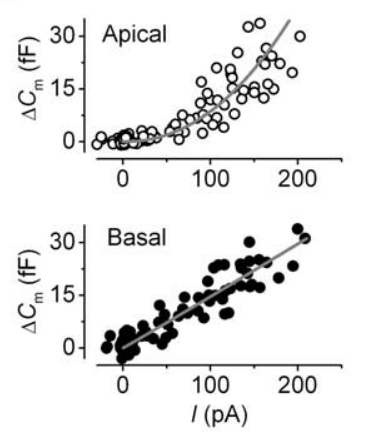

F
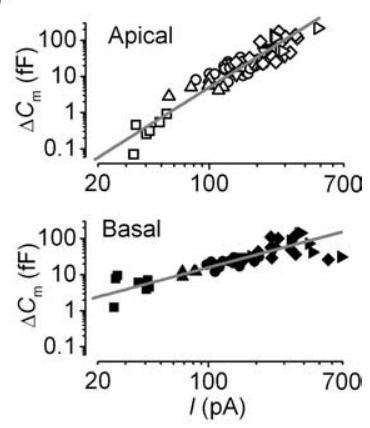

Figure 3. $\mathrm{Ca}^{2+}$ dependence of exocytosis in adult gerbil IHCS. $A, I_{\mathrm{Ca}}$ and $\Delta C_{\mathrm{m}}$ from apical (low-frequency, gray) and basal (high-frequency, black) IHCs. Voltage protocol is as in Figure 1. For clarity, only responses at -81 and $-11 \mathrm{mV}$ are shown. $\boldsymbol{B}$, Average peak $I-V$ and $\Delta C_{\mathrm{m}}-V$ curves in apical (P22-P34; $\left.n=15\right)$ and basal (P20-P30; $\left.n=13\right) \mathrm{IHC}$. C, Synaptic transfer functions obtained by plotting average $\Delta C_{\mathrm{m}}$ against the corresponding $I_{C a}$ between $-71 \mathrm{mV}$ and near $-11 \mathrm{mV}$ from $B$ for apical and basal IHCS. The fits are according to Equation 1.D, Single data points used to generate averages in C from apical and basal IHCS. Fits are as in C. E, Synaptic transfer functions from apical and basal IHCs showing average responses at the membrane potential at which the peak $I_{\mathrm{Ca}_{\mathrm{a}}}$ from the $I-V$ curve occurred (from approximately $-11 \mathrm{to}-1 \mathrm{mV}$ ) in different $\mathrm{Ca}^{2+}$ concentrations. Fits are using Equation 1. $\boldsymbol{F}$, Single data points used to generate averages in $\boldsymbol{E}$ from apical and basal IHCs plotted on a double logarithmic scale. Fits are as in $\boldsymbol{E}$. In both $\boldsymbol{E}$ and $\boldsymbol{F}$, the number of observations at each $\mathrm{Ca}^{2+}$ concentration $(0,0.6,1.3,2.5,5,10 \mathrm{~mm})$ were as follows: apical 7, 6, 26, 11, 13, 5 (from 26 IHCs); basal 7, 4, 15, 4, 11, 8 (from 16 IHCs). Error bars indicate SEM.

sensitivity of exocytosis in gerbil IHCs could be investigated by recording $\Delta C_{\mathrm{m}}$ during the superfusion of different extracellular $\mathrm{Ca}^{2+}$ concentrations (Augustine and Charlton, 1986). This would allow $\Delta C_{\mathrm{m}}$ to be measured at a membrane potential at which the number of open $\mathrm{Ca}^{2+}$ channels is maximal and constant (i.e., at the peak of the $I-V$ ) and the single- channel current would be changed only by the extracellular $\mathrm{Ca}^{2+}$ concentration. By using this method we avoid possible errors incurred when evaluating the $\mathrm{Ca}^{2+}$ dependence of exocytosis at positive membrane potentials, such as uncertainties about the identity of the current measured over this range (Augustine and Charlton, 1986), the voltage dependence of $\mathrm{Ca}^{2+}$ channel gating (Augustine et al., 1985), and the direct effect of membrane potential on the release process (Llinás et al., 1981). Varying the extracellular $\mathrm{Ca}^{2+}$ concentration gradually increased the size of both $I_{\mathrm{Ca}}$ and $\Delta C_{\mathrm{m}}$ in apical and basal IHCs (data not shown). The average $I_{\mathrm{Ca}}$ and corresponding $\Delta C_{\mathrm{m}}$ values obtained in these different $\mathrm{Ca}^{2+}$ concentrations are plotted as synaptic transfer functions in Figure $3 E$. The power values from fits using Equation 1 for apical and basal adult IHCs were $2.8 \pm 0.1$ (apical, $n=26$ ) and $1.2 \pm 0.1$ (basal, $n=16$; significant at $p<0.0001$ ), consistent with those obtained using different voltage steps in physiological extracellular $\mathrm{Ca}^{2+}$ $(1.3 \mathrm{~mm})$ (Fig. $3 C, D)$. Therefore, this suggests that the $\mathrm{Ca}^{2+}$ dependence of exocytosis measured in these cells is likely to represent the intrinsic properties of the synaptic machinery. The single data points used for the averages shown in Figure $3 E$ are plotted on a double logarithmic scale (Fig. 3F) to emphasize in more detail responses over the physiological $\mathrm{Ca}^{2+}$ range.

\section{Vesicle pool dynamics and ribbon number as a function of IHC frequency position}

The rate of neurotransmitter release in adult IHCs was studied by measuring $\Delta C_{\mathrm{m}}$ in response to depolarizing voltage steps to $-11 \mathrm{mV}$ of varying duration ( $2 \mathrm{~ms}$ to $1.5 \mathrm{~s}$; interstep interval was at least $11 \mathrm{~s}$ ), which allowed us to investigate the emptying of different synaptic vesicle pool populations (Fig. 4A). Although relatively short stimuli reveal the number of vesicles docked at the active zones [readily releasable pool (RRP)], longer steps induce the release of vesicles from a secondarily releasable pool (SRP) that is located farther away from the $\mathrm{Ca}^{2+}$ channels (Parsons et al., 1994; von Gersdorff et al., 1996; Moser and Beutner, 2000; Schnee et al., 2005). Similar to previous findings in mice (body temperature and $1.3 \mathrm{~mm} \mathrm{Ca}^{2+}$ ) (Johnson et al., 2005, 2007), voltage steps of up to $\sim 100 \mathrm{~ms}$ are likely to recruit mainly the RRP because the increase in $\Delta C_{\mathrm{m}}$ could be approximated with a single exponential (Fig. $4 B$ ). The size of the isolated RRP was slightly smaller in apical IHCs than in basal cells, as well as the initial release rate (apical, $387 \pm 32 \mathrm{fF} / \mathrm{s}$ or $10449 \pm 877$ vesicles/s, $n=13$; basal, $551 \pm 50 \mathrm{fF} / \mathrm{s}$ or $14883 \pm 1349$ vesicles/s, $n=13$, significant at $p<0.02$ from fits to individual IHCs), but the SRP in the former seemed to be larger. This behavior appears to reflect the higherorder $\mathrm{Ca}^{2+}$ dependence of exocytosis in apical IHCs (Fig. 3E). 
A

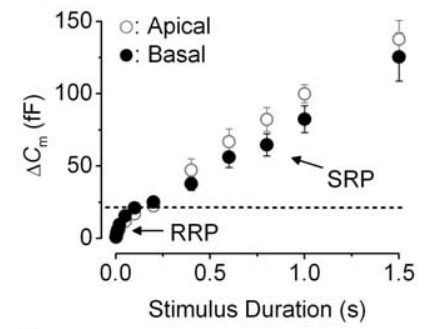

C

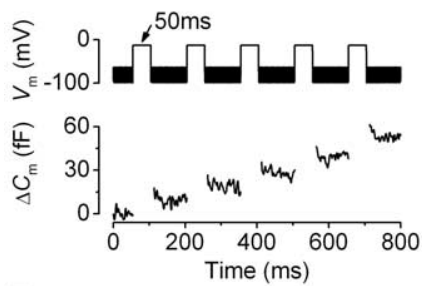

E
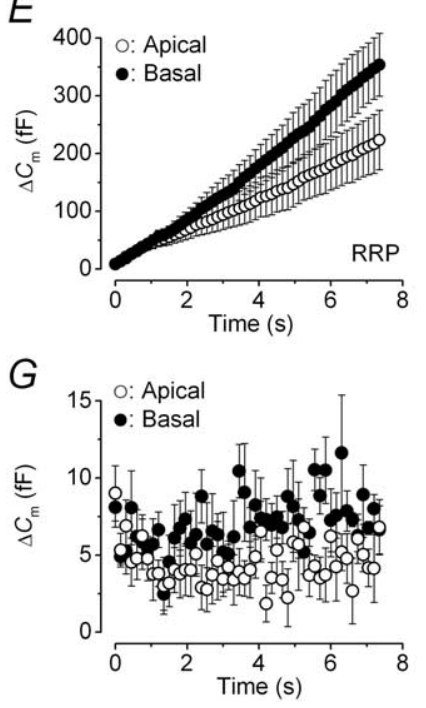

$B$

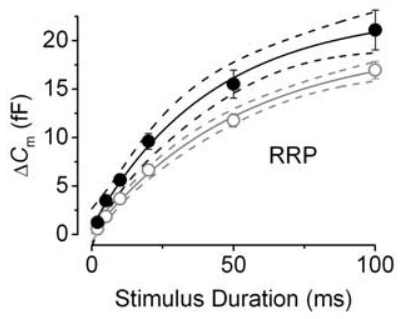

$D$

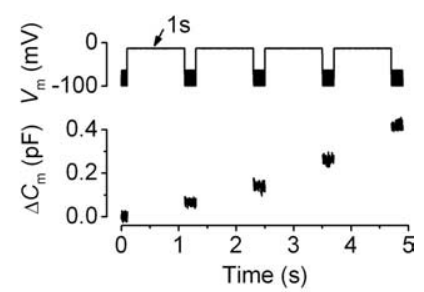

F

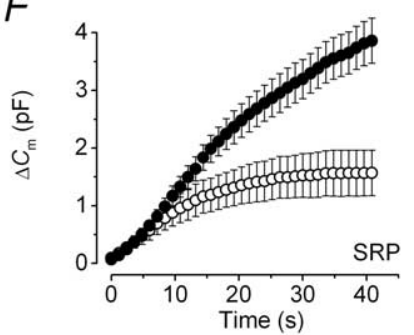

$H$

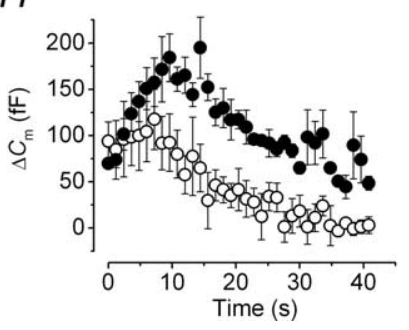

Figure 4. Kinetics of vesicle release and vesicle pool replenishment in adult gerbil IHCs. $A$, Average $\Delta C_{m}$ from 13 apical and 13 basal IHCs (P25-P60) in response to voltage steps from 2 ms to $1.5 \mathrm{~s}$ (to approximately $-11 \mathrm{mV}$ ) showing the RRP and SRP. $\boldsymbol{B}$, RRP (expanded from $\boldsymbol{A}$ ) approximated with single exponential functions (apical, maximum $\Delta C_{\mathrm{m}}=20 \pm 1 \mathrm{fF}, \tau=$ $52 \pm 9 \mathrm{~ms}$; basal, maximum $\Delta C_{\mathrm{m}}=23 \pm 2 \mathrm{ff}, \tau=42 \pm 11 \mathrm{~ms}$ ). The available RRP consisted of 534 (apical) and 619 (basal) vesicles using a conversion factor of 37 aF/vesicle (Lenzi et al., 1999). Dotted lines represent $95 \%$ confidence intervals for the fits. C, $D, \Delta C_{m}$ elicited using repetitive voltage steps to $-11 \mathrm{mV}$ of $50 \mathrm{~ms}$ and $1 \mathrm{~s}$ in duration to elicit the RRP and SRP, respectively. The interstep interval was $100 \mathrm{~ms}$ in Cand $200 \mathrm{~ms}$ in D. For clarity, only the first few steps are shown. The voltage protocol used is shown above the traces. $E, F$, Average cumulative $\Delta C_{\mathrm{m}}$ values obtained in response to the $50 \mathrm{~ms}$ ( 50 steps) and $1 \mathrm{~s}$ ( 35 steps) protocol, respectively, from seven apical and three basal IHCS. $\boldsymbol{G}, \boldsymbol{H}$, Individual $\Delta C_{\mathrm{m}}$ values from apical and basal IHCs measured after each voltage step from $\boldsymbol{E}$ and $\boldsymbol{F}$, respectively. Error bars indicate SEM.

The kinetics of exocytosis measured in this study are unlikely to be affected by slow endocytosis ( $\tau=7.5 \mathrm{~s}$ at room temperature) (Moser and Beutner, 2000) although it is likely to be faster at body temperature.

To calculate the release rate at single ribbon synapses in apical and basal IHCs, we counted them (see Fig. 6A) using an antibody against the presynaptic ribbon component RIBEYE (CtBP2) (Schmitz et al., 2000; Khimich et al., 2005). The total number of labeled ribbons per IHC did not vary significantly along the adult gerbil cochlea (apical, 20.6 $\pm 0.6, n=20$; basal, $22.4 \pm 0.8, n=$ 12 ), in agreement with the number of synaptic terminals previ-

ously determined using electron microscopy (Slepecky et al., 2000). Therefore, the vesicle release rate per ribbon was $\sim 507$ and 664 vesicles/s in apical and basal IHCs, respectively. This indicates that the difference in the total RRP release rate (Fig. $4 B$ ) was not attributable to variations in the total number of ribbons per cell or the $\mathrm{Ca}^{2+}$ load per synapse because a similar number of $\mathrm{Ca}^{2+}$ channels is likely to be present per ribbon.

Vesicle pool depletion could constitute a rate-limiting step in neurotransmitter release. Therefore, we investigated whether vesicle release from either the RRP or SRP was limited by the relative pool-refilling rates using repetitive stimulation. Figure 4, $C$ and $D$, shows examples of $\Delta C_{\mathrm{m}}$ when a train of $50 \mathrm{~ms}$ and $1 \mathrm{~s}$ steps to $-11 \mathrm{mV}$ were applied to investigate the depletion of the RRP and SRP, respectively (Fig. 4A,B). After repeated $50 \mathrm{~ms}$ steps, the cumulative $\Delta C_{\mathrm{m}}$ showed a near linear increase (Fig. $4 E$ ) indicating that the RRP appears to be able to replenish after each step in both apical and basal IHCs. The shallower slope observed in apical IHCs was a consequence of their smaller overall individual $\Delta C_{\mathrm{m}}$ (Fig. $4 G$ ) (apical, $4.5 \pm 0.2 \mathrm{fF}$; basal, $7.1 \pm 0.3 \mathrm{fF}$; twoway ANOVA; $p<0.0001)$. In contrast to basal IHCs, apical cells exhibited an initial small decline in the individual $\Delta C_{\mathrm{m}}$ with stimulus repetition (Fig. 4G), indicating that complete RRP replenishment did in fact not occur within $100 \mathrm{~ms}$. However, when a steady level of release was reached, the machinery was able to replenish this between steps. The first sign of a similar initial $\Delta C_{\mathrm{m}}$ decline in high-frequency IHCs was evident using either 50 or 20 ms interstep intervals (data not shown), although for these shorter intervals the recruitment of the SRP became evident, most likely attributable to $\mathrm{Ca}^{2+}$ accumulation. These findings suggest that repetitive stimuli could cause some small degree of vesicle pool depletion, which was never complete and was more evident in low-frequency IHCs. The cumulative $\Delta C_{\mathrm{m}}$ after longlasting $(1 \mathrm{~s})$ voltage steps showed SRP release saturation that was much more pronounced in apical IHCs (Fig. $4 F$ ). The earlier depletion of the SRP in apical IHCs, compared with basal cells, was also evident from the individual $\Delta C_{\mathrm{m}}$ (Fig. $4 H$ ). Interestingly, repetitive stimulation of the SRP resulted in an initial increase/potentiation in synaptic transmission before vesicle pool depletion occurred. Qualitatively similar results were also obtained when $\Delta C_{\mathrm{m}}$ was normalized to the size of $I_{\mathrm{Ca}}$ (data not shown). The observed facilitation could be explained by an initial $\mathrm{Ca}^{2+}$ accumulation after long-lasting depolarizations before vesicle depletion occurred.

\section{Functional coupling between $\mathrm{Ca}^{2+}$ channels and the RRP}

To determine the possible reason behind the different exocytotic $\mathrm{Ca}^{2+}$ dependence observed between low- and high-frequency adult gerbil IHCs (Fig. 3), we searched for possible variations in the functional coupling between $\mathrm{Ca}^{2+}$ channels and the synaptic machinery. This was done by investigating the morphology of ribbon synapses (Sobkowicz et al., 1982), the colocalization between ribbons and $\mathrm{Ca}^{2+}$ channels (Roberts et al., 1990; Tucker and Fettiplace, 1995), and the distribution of the proposed $\mathrm{Ca}^{2+}$ sensor otoferlin (Roux et al., 2006) as a function of IHC CF location. Figure 5, $A$ and $B$, shows a typical example of the morphology of IHC presynaptic ribbons using transmission electron microscopy. Although all ribbons observed $(n=16)$ in basal IHCs showed an ellipsoid morphology, as described previously in adult mouse IHCs (Sobkowicz et al., 1982; Khimich et al., 2005), those in low-frequency cells were all spherical $(n=10)$. The ribbon width was similar between apical and basal IHCs (spherical ribbons, $114 \pm 20 \mathrm{~nm}, n=6$; ellipsoid ribbons, $94 \pm 7 \mathrm{~nm}$, $n=9$; dimensions were only from ribbons in which accurate 
A

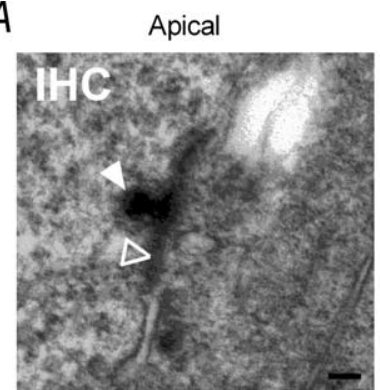

C
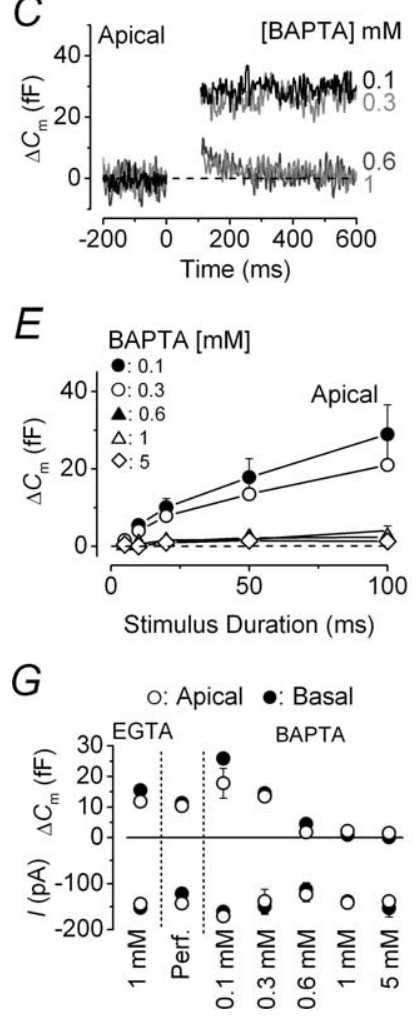

$B$
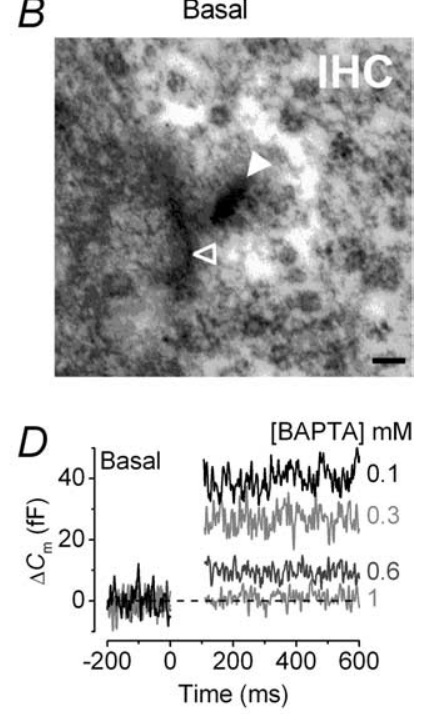

$F$

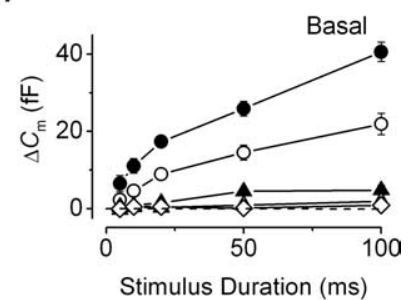

$H$

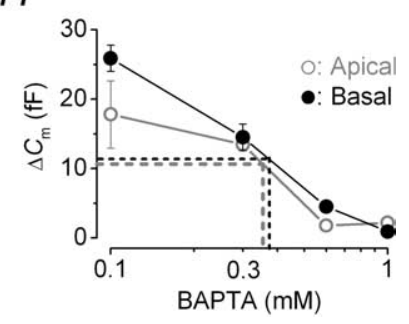

Figure 5. Shape of ribbon synapses and their functional coupling with $\mathrm{Ca}^{2+}$ channels. $A, B$, Typical cross-sectional profiles of synaptic ribbons from an apical and a basal IHC, respectively. Note that the ribbon (filled arrowheads) in the apical IHC $(\boldsymbol{A})$ had a round cross-sectional profile, whereas that in the basal cell $(\boldsymbol{B})$ was elongated in shape. Open arrowheads indicate synaptic membrane thickenings. Scale bar, $100 \mathrm{~nm} . \boldsymbol{C}, \boldsymbol{D}, \Delta C_{\mathrm{m}}$ from apical and basal IHCs, respectively, in response to a $100 \mathrm{~ms}$ voltage step (to approximately $-11 \mathrm{mV}$ ) using different intracellular BAPTA concentrations (indicated next to the traces). $\boldsymbol{E}, \boldsymbol{F}$, Average $\Delta \boldsymbol{C}_{\mathrm{m}}$ to voltage steps from 5 to $100 \mathrm{~ms}$ in apical and basal IHCs. $G$, Average $\Delta C_{\mathrm{m}}$ and peak $I_{\mathrm{Ca}}$ at $50 \mathrm{~ms}$ from data shown in $\boldsymbol{E}$ and $\boldsymbol{F}$, including those in EGTA from Figure $4 B$. Number of cells in EGTA (1 mM), perforatedpatch, and different concentrations of BAPTA $(0.1,0.3,0.6,1,5 \mathrm{~mm})$ are as follows: apical, 13,5 , $3,5,4,5,3$; basal, $13,7,3,4,5,4,3$. $\boldsymbol{H}$, Estimation of the endogenous buffer concentration. The perforated-patch values of $\Delta C_{m}$ were extrapolated (dotted lines) to those obtained using different BAPTA concentrations (data as in $\mathbf{G}$ ). Error bars indicate SEM.

measurements could be made), but their height was significantly bigger in the latter cells (spherical, $120 \pm 19 \mathrm{~nm}$; ellipsoid, $198 \pm$ $10 \mathrm{~nm}, p<0.002$ ). These dimensions are also comparable with those obtained in other species (Nouvian et al., 2006).

Because the ribbon shape was different between the two CF locations, we investigated whether the colocalization between vesicle release sites and $\mathrm{Ca}^{2+}$ channels was affected by measuring $\Delta C_{\mathrm{m}}$ in the presence of different intracellular BAPTA concentrations (Fig. $5 \mathrm{C}-\mathrm{H}$ ). BAPTA is a $\mathrm{Ca}^{2+}$ chelator with faster binding kinetics than EGTA and therefore capable of buffering $\mathrm{Ca}^{2+}$ elevations closer to their source (Neher, 1998). For these experi-

ments, RRP release was studied using a protocol similar to that described in Figure $4 B$ (voltage steps up to $100 \mathrm{~ms}$, RRP) and applied to apical and basal IHCs using different BAPTA concentrations (Fig. 5C,D). The release of the RRP was evident when IHCs were buffered with 0.1 and $0.3 \mathrm{~mm}$ BAPTA, but was greatly reduced in both cochlear regions with $\geq 0.6 \mathrm{~mm}$ BAPTA (Fig. $5 E, F)$ relative to recordings in $1 \mathrm{~mm}$ EGTA (Fig. 5G) $(p<$ 0.001 ), suggesting that a comparable distance is present between $\mathrm{Ca}^{2+}$ channels and release sites in both apical and basal cells. Perforated-patch recordings (Fig. 5G) were used to determine whether potential position-dependent differences in the endogenous $\mathrm{Ca}^{2+}$ buffering could affect the coupling between $\mathrm{Ca}^{2+}$ and exocytosis independent of $\mathrm{Ca}^{2+}$ channel position. Figure $5 \mathrm{H}$ shows that the concentration of the endogenous mobile $\mathrm{Ca}^{2+}$ buffer was $\sim 0.38 \mathrm{~mm}$ BAPTA in basal IHCs and $0.35 \mathrm{~mm}$ BAPTA in apical cells.

Because the relative distance of the $\mathrm{Ca}^{2+}$ channels with release sites was comparable in low- and high-frequency IHCs, we investigated whether a difference in the $\mathrm{Ca}^{2+}$ dependence of exocytosis could be linked with a tonotopic variation in the expression of otoferlin (Schug et al., 2006), the proposed $\mathrm{Ca}^{2+}$ sensor of exocytosis in cochlear hair cells (Roux et al., 2006; Beurg et al., 2008). To determine whether otoferlin was present at IHC active zones, we performed double-staining experiments with either CtBP2 (RIBEYE) (Fig. 6A) or NF200 (Fig. 6B), which stains presynaptic ribbon synapses or afferent fibers, respectively. We found no obvious difference in otoferlin staining along the tonotopic axis of adult gerbil cochleae (P22-P120, qualitative judgment from observations on $>200$ sections), and although it is clearly involved in exocytosis (Roux et al., 2006; Beurg et al., 2008), it seems unlikely that it accounts for the difference in $\mathrm{Ca}^{2+}$ dependence observed in our study. Similarly, the expression of otoferlin in mouse IHCs appears to be constant throughout development (Roux et al., 2006) and again is unlikely to be responsible for the linearization in the $\mathrm{Ca}^{2+}$ dependence of exocytosis observed in these cells during maturation (Johnson et al., 2005). Moreover, the apparent absence of otoferlin from the retina (Yasunaga et al., 1999) indicates that it cannot be responsible for the linear $\mathrm{Ca}^{2+}$ dependence observed at ribbon synapses of rod photoreceptors (Thoreson et al., 2004). Although otoferlin seemed to be more concentrated below the nucleus of IHCs, it was not exclusively colocalized with either CtBP2-immunopositive ribbons (Fig. 6A, Merge) or NF200 afferents (Fig. 6B). The homogenous distribution of otoferlin throughout IHCs has also been shown in the mouse (Roux et al., 2006) and could indicate a more ubiquitous role for otoferlin in vesicle-membrane trafficking (Yasunaga et al., 1999). Finally, it is also crucial to point out that IHCs from hypothyroid rats did not express otoferlin but still showed exocytosis (Brandt et al., 2007).

\section{Discussion}

Exocytosis was investigated at IHC ribbon synapses from the gerbil cochlea using capacitance measurements. Prehearing IHCs and low-frequency $(\sim 300 \mathrm{~Hz})$ adult cells exhibited a higherorder exocytotic $\mathrm{Ca}^{2+}$ dependence than that observed in highfrequency $(\sim 30 \mathrm{kHz})$ adult cells. This position-dependent difference in adult IHCs appeared to be correlated with ribbon synapse shape but was not related to the expression level of the $\mathrm{Ca}^{2+}$ sensor otoferlin nor the colocalization between $\mathrm{Ca}^{2+}$ channels and release sites. Repetitive stimulation of adult IHCs showed that vesicle pool refilling could be rate limiting for the release of the SRP, but not the RRP, with high-frequency IHCs being able to sustain greater release rates. Using the intact gerbil organ of Corti, 
A
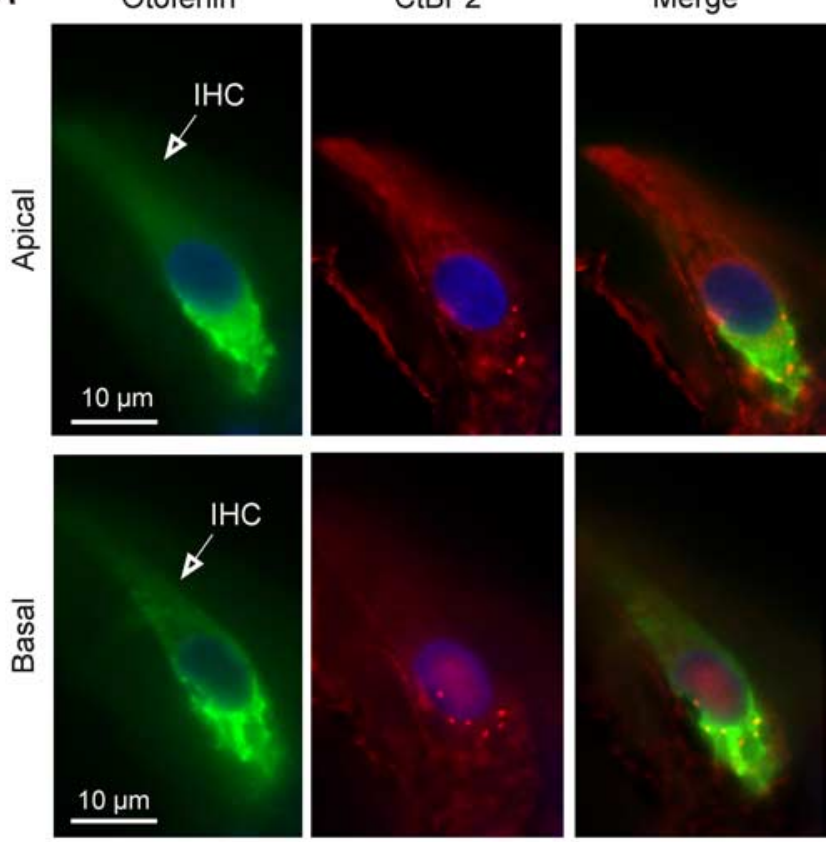

B
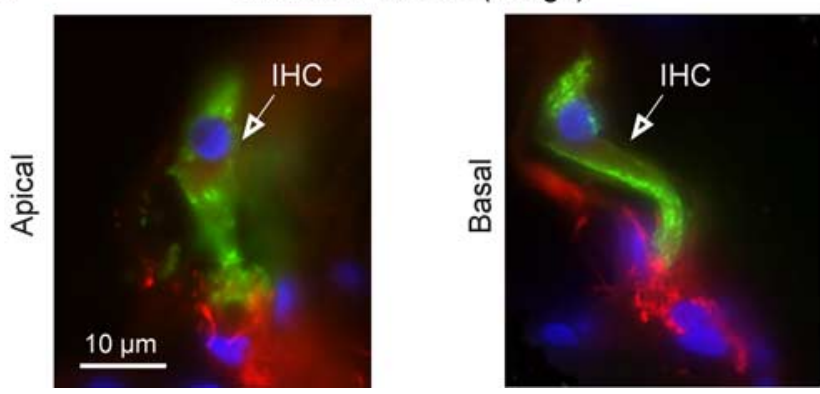

Figure 6. Distribution of otoferlin and ribbon synapses in low- and high-frequency adult gerbil IHCS. A, IHCs from apical and midbasal cochlear regions of the adult gerbil (P22) were immunostained for the synaptic vesicle protein otoferlin (green) and presynaptic ribbon component RIBEYE ( $C t B P 2$, red). Note that CtBP2 is exclusively localized in the basal pole of IHCs in a dot-like pattern. $\boldsymbol{B}$, IHCs from apical and midbasal cochlear regions (P120) were immunostained for both ot oferlin (green) and NF200 (red), which labeled auditory afferent fibers. Nuclei were stained with DAPI (blue). IHCs are indicated by open arrows.

we have provided the first evidence for tonotopic differences in exocytosis at IHC ribbon synapses.

\section{The tonotopicity of gerbil IHC ribbon synapses}

In the mouse cochlea, IHC ribbon synapses change from spherical to ellipsoid during maturation (Sobkowicz et al., 1982). We found that although ribbons in high-frequency IHCs of adult gerbils were ellipsoid, those present in lowfrequency cells were spherical, suggesting that the latter could retain some immature characteristics. However, the developmental improvement in the $\mathrm{Ca}^{2+}$ efficiency of exocytosis in apical and basal IHCs suggests that synaptic maturation did occur in these cells (Beutner and Moser, 2001; Johnson et al., 2005). This leads us to assume that the position-dependent variation in mature ribbon shape is determined by the different functional requirements of low- and high-frequency IHCs and not by the stage of development.

In the mature cochlea, basal-coil IHCs respond to highfrequency sound with depolarizing receptor potentials, initiated by the transducer current at the hair bundle. For high-frequency tones, cell membrane filtering prevents phase-locking above $\sim 3.5 \mathrm{kHz}$ (Palmer and Russell, 1986) so receptor potentials are graded and sustained to represent sound intensity and stimulus envelope. The linear $\mathrm{Ca}^{2+}$ dependence $(N \approx 1.0)$ and high $\mathrm{Ca}^{2+}$ efficiency of the synaptic machinery observed in high-frequency IHCs $(\sim 30 \mathrm{kHz})$ ensure that information is accurately encoded at ribbon synapses, as suggested previously in apical mouse IHCs ( $\sim 3 \mathrm{kHz}$ ) (Brandt et al., 2005; Johnson et al., 2005) and photoreceptors (Thoreson et al., 2004). In contrast, low-frequency IHCs are phase-locked to sound stimulation such that their receptor potentials are graded to intensity, similar to basal cells, but have an additional phasic component representing the sound frequency (Dallos, 1985). This phasic component, likely to be the dominant component in apical gerbil $(\sim 300 \mathrm{~Hz})$ but not in apical mouse $(\sim 3 \mathrm{kHz})$ IHCs, could be emphasized by the somewhat unexpected finding of a higher-order exocytotic $\mathrm{Ca}^{2+}$ dependence in apical cells $(N \approx 2.2-2.8)$. This view is reinforced by the resemblance of their cooperative nature to that of prehearing IHCs [gerbils (Fig. 2); mice (Johnson et al., 2005)], because AP activity shares some degree of similarity to the phasic nature of low-frequency adult cells. A functional consequence of the higher $\mathrm{Ca}^{2+}$ cooperativity of exocytosis in low-frequency IHCs could be the impedance of signaling low-intensity sound stimuli and may contribute to the higher auditory threshold of these cells (Ryan, 1976). Another functional representation of variations in IHC exocytosis could be in the firing characteristics of single auditory afferent fibers that are known to vary tonotopically along the gerbil cochlea, potentially extending the dynamic range of firing rate responses in high-frequency fibers (Ohlemiller and Siegel, 1994). Although some of these differences (spontaneous and sound induced firing rates) could originate from tonotopic variations in IHC exocytosis, it is difficult to correlate these data because afferent activity is driven by single release sites, whereas IHC exocytosis is an integral over the entire cell. Moreover, other factors including postsynaptic efferent modulation and different IHC receptor characteristics could also influence afferent responses.

A compelling observation was the apparent relationship between ribbon morphology and IHC receptor characteristics, with spherical ribbons mainly supporting phasic neurotransmission whereas the ellipsoid shape appears to promote sustained and graded release (Sterling and Matthews, 2005; Moser et al., 2006). However, the possible mechanism involved in linking ribbon shape and function is currently unknown. In contrast to the gerbil, most lower vertebrate auditory hair cells that respond phasically to sound and appear to have mainly spherical ribbons [lizard (Mulroy, 1986); chick (Martinez-Dunst et al., 1997); turtle (Schnee et al., 2005); bullfrog (Keen and Hudspeth, 2006)] show a linear $\mathrm{Ca}^{2+}$ dependence of exocytosis (Schnee et al., 2005; Keen and Hudspeth, 2006) that does not vary with CF (Schnee et al., 2005). However, a greater $\mathrm{Ca}^{2+}$ cooperativity was evident for membrane potentials negative to $-55 \mathrm{mV}$ that elicited small $I_{\mathrm{Ca}}$ [see Keen and Hudspeth (2006), their Fig. 5C], probably reflecting the intrinsic properties of the synaptic machinery in these hair cells. The kinetics of exocytosis in turtle hair cells do show tonotopic variation that can be modeled independent from exocytotic $\mathrm{Ca}^{2+}$ sensitivity (Schnee et al., 2005). However, our findings suggest that the $\mathrm{Ca}^{2+}$ dependence of exocytosis could be more fundamental in determining tonotopic differences in mammalian neurotransmitter release and should be considered when modeling the synaptic vesicle cycle. 


\section{Mechanisms controlling $\mathrm{Ca}^{2+}$ dependence at IHC synapses} The tonotopic variation in the $\mathrm{Ca}^{2+}$ dependence of exocytosis in adult gerbil IHCs is likely to result from a different functional coupling between $\mathrm{Ca}^{2+}$ entry and vesicle release, which could be determined by their relative distance (Brandt et al., 2005). In this situation, the $\mathrm{Ca}^{2+}$ dependence of the synaptic machinery would be intrinsically high order, regardless of cochlear position, but a closer (nanodomain) coupling to the channels in basal IHCs could give an "apparent" impression of a linear $\mathrm{Ca}^{2+}$ dependence over a physiological voltage range. Exocytosis in gerbil IHCs was almost completely prevented using $0.6 \mathrm{~mm}$ BAPTA, suggesting that docked vesicles are within $50 \mathrm{~nm}$ from $\mathrm{Ca}^{2+}$ channels in both cochlear regions (Naraghi and Neher, 1997; Neher, 1998). Therefore, a nanodomain control of exocytosis is likely to be present regardless of CF location, which seems to contradict the above hypothesis. However, we found that the tonotopic difference in the apparent $\mathrm{Ca}^{2+}$ dependence of exocytosis (Fig. $3 \mathrm{C}$ ) seemed to be an intrinsic property of the IHCs synaptic machinery (Fig. $3 E$ ), possibly resulting from the differential expression of $\mathrm{Ca}^{2+}$-sensing molecules or promoters of exocytosis (Jahn et al., 2003). Although otoferlin is clearly involved in exocytosis (Roux et al., 2006; Beurg et al., 2008), our findings, together with recently published evidence (see Results), makes it an unlikely candidate for the linearization of the $\mathrm{Ca}^{2+}$ dependence of exocytosis observed in this study and indeed in mature mouse IHCs (Johnson et al., 2005, 2007). Therefore, another $\mathrm{Ca}^{2+}$ sensor could be involved and/or the expression levels of synaptic proteins such as SNAP25 and synaptobrevin 1 (Sendin et al., 2007) or the synaptic chaperone cysteine-string protein (Eybalin et al., 2002) could influence $\mathrm{Ca}^{2+}$-exocytosis coupling. The expression of such molecules could be regulated by spontaneous AP activity present during early stages of development (Gu and Spitzer, 1995). Indeed, abnormal AP activity in prehearing IHCs prevented the developmental linearization in exocytotic $\mathrm{Ca}^{2+}$ dependence (Johnson et al., 2007). Therefore, in the maturing gerbil cochlea, the selective expression of synaptic molecules could be dictated by position-dependent differences in AP frequency. Although this has yet to be investigated, $I_{\mathrm{Ca}}$ in basal IHCs can support a higher AP frequency than apical cells (Johnson and Marcotti, 2008).

\section{Kinetics of vesicle release in adult IHCs}

At least two distinct kinetic components of vesicle release were evident in adult gerbil IHCs: a rapid component (RRP) and a slower but larger component (SRP). Although the SRP showed a nearly constant release rate up to at least $1.5 \mathrm{~s}$ in both cochlear regions, the RRP saturated with time constants of $52 \mathrm{~ms}$ (apical) and $42 \mathrm{~ms}$ (basal). Because $I_{\mathrm{Ca}}$ in IHCs exhibits very little inactivation for stimuli $\leq 100 \mathrm{~ms}$ (Johnson and Marcotti, 2008), the depletion of docked vesicles (apical, 534; basal, 619) was the most likely explanation for this initial component. The RRP in gerbil IHCs corresponded to $\sim 26$ (apical) and 28 (basal) vesicles per active zone, which was well correlated with anatomical observations ( $\leq 30$ vesicles per synapse in mouse) (Khimich et al., 2005) and auditory afferent recordings ( $\sim 12$ vesicles per synapse in rat) (Goutman and Glowatzki, 2007).

IHC afferent synapses require rapid vesicle pool replenishment to continuously encode sound information. Although the release of vesicles from within the RRP was slightly reduced by repetitive stimulation, which was more evident in the apical region, IHCs could maintain exocytosis for prolonged time periods. Therefore, vesicle fusion and not their replenishment was the main rate limiting step for exocytosis, as also found in lower vertebrates (Schnee et al., 2005). Rapid RRP replenishment has also been observed in guinea pig IHCs using two-photon imaging (Griesinger et al., 2005). In contrast, the SRP was more susceptible to pool depletion after repetitive stimulation, especially in low-frequency IHCs. Possible explanations for this could be a lower cytoplasmic vesicle density in apical cells and/or the poorer replenishment of ribbon-associated synaptic vesicles. Therefore, the synaptic machinery in adult mammalian IHCs appears to be specifically designed for sustaining neurotransmitter release with high-frequency cells being more indefatigable.

\section{References}

Augustine GJ, Charlton MP (1986) Calcium dependence of presynaptic calcium current and postsynaptic response at the squid giant synapse. J Physiol 381:619-640.

Augustine GJ, Charlton MP, Smith SJ (1985) Calcium entry and transmitter release at voltage-clamped nerve terminals of squid. J Physiol 367:163-181.

Beurg M, Safieddine S, Roux I, Bouleau Y, Petit C, Dulon D (2008) Calcium- and otoferlin-dependent exocytosis by immature outer hair cells. J Neurosci 28:1798-1803.

Beutner D, Moser T (2001) The presynaptic function of mouse cochlear inner hair cells during development of hearing. J Neurosci 21:4593-4599.

Brandt A, Striessnig J, Moser T (2003) CaV1.3 channels are essential for development and presynaptic activity of cochlear inner hair cells. J Neurosci 23:10832-10840.

Brandt A, Khimich D, Moser T (2005) Few $\mathrm{Ca}_{\mathrm{V}} 1.3$ channels regulate the exocytosis of a synaptic vesicle at the hair cell ribbon synapse. J Neurosci 25:11577-11585.

Brandt N, Kuhn S, Münkner S, Braig C, Winter H, Blin N, Vonthein R, Knipper M, Engel J (2007) Thyroid hormone deficiency affects postnatal spiking activity and expression of $\mathrm{Ca}^{2+}$ and $\mathrm{K}^{+}$channels in rodent inner hair cells. J Neurosci 27:3174-3186.

Cody AR, Russell IJ (1987) The responses of hair cells in the basal turn of the guinea-pig cochlea to tones. J Physiol 383:551-569.

Dallos P (1985) Response characteristics of mammalian cochlear hair cells. J Neurosci 5:1591-1608.

Dodge FA Jr, Rahamimoff R (1967) Co-operative action of calcium ions in transmitter release at the muscular junction. J Physiol 193:419-432.

Eybalin M, Renard N, Aure F, Safieddine S (2002) Cysteine-string protein in inner hair cells of the organ of Corti: synaptic expression and upregulation at the onset of hearing. Eur J Neurosci 15:1409-1420.

Fettiplace R, Fuchs PA (1999) Mechanisms of hair cell tuning. Annu Rev Physiol 61:809-834.

Fuchs PA (2005) Time and intensity coding at the hair cell's ribbon synapse. J Physiol 566:7-12.

Glowatzki E, Fuchs PA (2002) Transmitter release at the hair cell ribbon synapse. Nat Neurosci 5:147-154.

Goutman JD, Glowatzki E (2007) Time course and calcium dependence of transmitter release at a single ribbon synapse. Proc Natl Acad Sci U S A 104:16341-16346.

Greenwood DD (1990) A cochlear frequency-position function for several species-29 years later. J Acoust Soc Am 87:2592-2605.

Griesinger CB, Richards CD, Ashmore JF (2005) Fast vesicle replenishment allows indefatigable signalling at the first auditory synapse. Nature 435:212-215.

Gu X, Spitzer NC (1995) Distinct aspects of neuronal differentiation encoded by frequency of spontaneous $\mathrm{Ca} 2+$ transients. Nature 375:784-787.

Hackney CM, Mahendrasingam S, Penn A, Fettiplace R (2005) The concentration of calcium buffering proteins inmammalian cochlear hair cells. J Neurosci 25:7867-7875.

Jahn R, Lang T, Südhof TC (2003) Membrane fusion. Cell 112:519-533.

Jia S, Dallos P, He DZ (2007) Mechanoelectric transduction of adult inner hair cells. J Neurosci 27:1006-1014.

Johnson SL, Marcotti W (2008) Biophysical properties of $\mathrm{Ca}_{\mathrm{V}} 1.3$ calcium channels in gerbil inner hair cells. J Physiol 586:1029-1042.

Johnson SL, Thomas MV, Kros CJ (2002) Membrane capacitance measurement using patch clamp with integrated self-balancing lock-in amplifier. Pflugers Arch 443:653-663.

Johnson SL, Marcotti W, Kros CJ (2005) Increase in efficiency and reduc- 
tion in $\mathrm{Ca}^{2+}$ dependence of exocytosis during development of mouse inner hair cells. J Physiol 563:177-191.

Johnson SL, Adelman JP, Marcotti W (2007) Genetic deletion of SK2 channels in mouse inner hair cells prevents the developmental linearization in the $\mathrm{Ca}^{2+}$ dependence of exocytosis. J Physiol 583:631-646.

Keen EC, Hudspeth AJ (2006) Transfer characteristics of the hair cell's afferent synapse. Proc Natl Acad Sci U S A 103:5537-5542.

Khimich D, Nouvian R, Pujol R, Tom Dieck S, Egner A, Gundelfinger ED, Moser T (2005) Hair cell synaptic ribbons are essential for synchronous auditory signalling. Nature 434:889-894.

Kros CJ, Ruppersberg JP, Rüsch A (1998) Expression of a potassium current in inner hair cells during development of hearing in mice. Nature 394:281-284.

Lenzi D, Runyeon JW, Crum J, Ellisman MH, Roberts WM (1999) Synaptic vesicle populations in saccular hair cells reconstructed by electron tomography. J Neurosci 19:119-132.

Llinás R, Steinberg IZ, Walton K (1981) Relationship between presynaptic calcium current and postsynaptic potential in squid giant synapse. Biophys J 33:323-351.

Marcotti W, Johnson SL, Holley MC, Kros CJ (2003a) Developmental changes in the expression of potassium currents of embryonic, neonatal and mature mouse inner hair cells. J Physiol 548:383-400.

Marcotti W, Johnson SL, Rusch A, Kros CJ (2003b) Sodium and calcium currents shape action potentials in immature mouse inner hair cells. J Physiol 552:743-761.

Marcotti W, Johnson SL, Kros CJ (2004) A transiently expressed SK current sustains and modulates action potential activity in immature mouse inner hair cells. J Physiol 560:691-708.

Martinez-Dunst C, Michaels RL, Fuchs PA (1997) Release sites and calcium channels in hair cells of the chick's cochlea. J Neurosci 17:9133-9144.

Moser T, Beutner D (2000) Kinetics of exocytosis and endocytosis at the cochlear inner hair cell afferent synapse of the mouse. Proc Natl Acad Sci U S A 97:883-888.

Moser T, Neef A, Khimich D (2006) Mechanisms underlying the temporal precision of sound coding at the inner hair cell ribbon synapse. J Physiol 576:55-62.

Müller M (1996) The cochlear place-frequency map of the adult and developing Mongolian gerbil. Hear Res 94:148-156.

Mulroy MJ (1986) Patterns of afferent synaptic contacts in the alligator Lizard's cochlea. J Comp Neurol 248:263-271.

Naraghi M, Neher E (1997) Linearized buffered $\mathrm{Ca}^{2+}$ diffusion in microdomains and its implications for calculation of $\left[\mathrm{Ca}^{2+}\right]$ at the mouth of a calcium channel. J Neurosci 17:6961-6973.

Neef A, Khimich D, Pirih P, Riedel D, Wolf F, Moser T (2007) Probing the mechanism of exocytosis at the hair cell ribbon synapse. J Neurosci 27:12933-12944.

Neher E (1998) Vesicle pools and $\mathrm{Ca}^{2+}$ microdomains: new tools for understanding their roles in neurotransmitter release. Neuron 20:389-399.

Nouvian R, Beutner D, Parsons TD, Moser T (2006) Structure and function of the hair cell ribbon synapse. J Membr Biol 209:153-165.

Ohlemiller KK, Siegel JH (1994) Cochlear basal and apical differences reflected in the effects of cooling on responses of single auditory nerve fibers. Hear Res 80:174-190.
Palmer AR, Russell IJ (1986) Phase-locking in the cochlear nerve of the guinea-pig and its relation to the receptor potential of inner hair-cells. Hear Res 24:1-15.

Parsons TD, Lenzi D, Almers W, Roberts WM (1994) Calcium-triggered exocytosis and endocytosis in an isolated presynaptic cell: capacitance measurements in saccular hair cells. Neuron 13:875-883.

Platzer J, Engel J, Schrott-Fischer A, Stephan K, Bova S, Chen H, Zheng H, Striessnig J (2000) Congenital deafness and sinoatrial node dysfunction in mice lacking class D L-type $\mathrm{Ca}^{2+}$ channels. Cell 102:89-97.

Roberts WM, Jacobs RA, Hudspeth AJ (1990) Colocalization of ion channels involved in frequency selectivity and synaptic transmission at presynaptic active zones of hair cells. J Neurosci 10:3664-3684.

Roux I, Safieddine S, Nouvian R, Grati M, Simmler MC, Bahloul A, Perfettini I, Le Gall M, Rostaing P, Hamard G, Triller A, Avan P, Moser T, Petit C (2006) Otoferlin, defective in a human deafness form, is essential for exocytosis at the auditory ribbon synapse. Cell 127:277-289.

Ryan A (1976) Hearing sensitivity of the Mongolian gerbil, Meriones unguiculatis. J Acoust Soc Am 5:1222-1226.

Schmitz F, Königstorfer A, Südhof TC (2000) RIBEYE, a component of synaptic ribbons: a protein's journey through evolution provides insight into synaptic ribbon function. Neuron 28:857-872.

Schnee ME, Lawton DM, Furness DN, Benke TA, Ricci AJ (2005) Auditory hair cell-afferent fiber synapses are specialized to operate at their best frequencies. Neuron 47:243-254.

Schug N, Braig C, Zimmermann U, Engel J, Winter H, Ruth P, Blin N, Pfister M, Kalbacher H, Knipper M (2006) Differential expression of otoferlin in brain, vestibular system, immature and mature cochlea of the rat. Eur J Neurosci 24:3372-3380.

Sendin G, Bulankina AV, Riedel D, Moser T (2007) Maturation of ribbon synapses in hair cells is driven by thyroid hormone. J Neurosci 27:3163-3173.

Slepecky NB, Galsky MD, Swartzentruber-Martin H, Savage J (2000) Study of afferent nerve terminals and fibers in the gerbil cochlea: distribution by size. Hear Res 144:124-134.

Sobkowicz HM, Rose JE, Scott GE, Slapnick SM (1982) Ribbon synapses in the developing intact and cultured organ of Corti in the mouse. J Neurosci 2:942-957.

Sterling P, Matthews G (2005) Structure and function of ribbon synapses. Trends Neurosci 28:20-29.

Thoreson WB, Rabl K, Townes-Anderson E, Heidelberger R (2004) A highly $\mathrm{Ca}^{2+}$-sensitive pool of vesicles contributes to linearity at the rod photoreceptor ribbon synapse. Neuron 42:595-605.

Tucker T, Fettiplace R (1995) Confocal imaging of calcium microdomains and calcium extrusion in turtle hair cells. Neuron 15:1323-1335.

von Gersdorff H, Vardi E, Matthews G, Sterling P (1996) Evidence that vesicles on the synaptic ribbon of retinal bipolar neurons can be rapidly released. Neuron 16:1221-1227.

Woolf NK, Ryan AF (1984) The development of auditory function in the cochlea of the mongolian gerbil. Hear Res 13:277-283.

Yasunaga S, Grati M, Cohen-Salmon M, El-Amraoui A, Mustapha M, Salem N, El-Zir E, Loiselet J, Petit C (1999) A mutation in OTOF, encoding otoferlin, a FER-1-like protein, causes DFNB9, a nonsyndromic form of deafness. Nat Genet 21:363-369. 